\title{
The Role and Place of Albumin in Modern Transfusiology. Problems and Ways to Solve Them
}

\author{
Andrey Belousov* \\ Laboratory of Applied Nanotechnology of Belousov, Ukraine \\ *Corresponding author: Andrey Belousov, Laboratory of Applied Nanotechnology of Belousov, Kharkov Medical Academy of \\ Postgraduate Education, Ukraine.
}

To Cite This Article: Andrey Belousov. The Role and Place of Albumin in Modern Transfusiology.Problems and Ways to Solve Them. Am J Biomed Sci \& Res. 2019 - 3(4). AJBSR.MS.ID.000687. DOI: 10.34297/AJBSR.2019.03.000687

Received: June 07, 2019 | Published: June 20, 2019

\begin{abstract}
The advantages of albumin over less costly alternative fluids continue to be debated. Many scientific articles were devoted to the clinical analysis of the use of albumin in acute illness as well as its comparison with other fluid regimens. However, the lack of fundamental knowledge about the physical and chemical properties of commercial albumin generates many unpromising discussions about the effectiveness of the use of albumin among practitioners and medical scientists. The manuscript provides information about the different variants of commercial albumin, the mechanisms of their action, indications and contraindications to use. The main purpose of this article is to objectively show the failure of generalizing conclusions and recommendations on the clinical use of commercial albumin, taking into account its various physical and chemical characteristics. To date, all studies should be conducted either in the form of a comparative analysis of a specific clinical effect, or within the framework of studies of only one brand of albumin. Otherwise, generalizing the conclusions, the recommendations on the use of different forms of albumin are not correct and generate a lot of useless of the discussions. The presented information is based on fundamental knowledge of physical and chemical properties of commercial albumin. This manuscript is not only educational information, but also is scientific guide for clinicians.
\end{abstract}

Keywords: Albumin, Physical and Chemical Properties, Indications, Contraindications

\section{Background}

Human albumin (HA) or serum albumin is encoded by the ALB gene and is the most abundant plasma protein in mammals. Human albumin is essential for maintaining the osmotic pressure needed for proper distribution of body fluids between intravascular compartments and body tissues. Human albumin also acts as a plasma carrier by non-specifically binding several hydrophobic steroid hormones and as a transport protein for hemin and fatty acids. The advantages of albumin over less costly alternative fluids continue to be debated. Meta-analyses focusing on survival have been inconclusive, and other clinically relevant endpoints have not been systematically addressed. Database searches (MEDLINE, EMBASE, Cochrane Library) and other methods were used to identify randomized controlled trials comparing albumin with crystalloid, artificial colloid, no albumin or lower-dose albumin. Major findings for all endpoints were extracted and summarized $[1,2]$.

Seventy-nine randomized trials with a total of 4755 patients were included. No significant treatment effects were detectable in $20 / 79$ (25\%) trials. In cardiac surgery, albumin administration resulted in lower fluid requirements, higher colloid oncotic pressure, reduced pulmonary edema with respiratory impairment and greater hemodilution compared with crystalloid and hydroxyethyl starch increased postoperative bleeding. In noncardiac surgery, fluid requirements, and pulmonary and intestinal edema were decreased by albumin compared with crystalloid. In hypoalbuminemia, higher doses of albumin reduced morbidity. In ascites, albumin reduced hemodynamic derangements, morbidity and length of stay and improved survival after spontaneous bacterial peritonitis. In sepsis, albumin decreased pulmonary edema and respiratory dysfunction compared with crystalloid, while hydroxyethyl starch induced abnormalities of hemostasis. Complications were lowered by albumin compared with crystalloid in burn patients. Albumin-containing therapeutic regimens improved outcomes after brain injury [3].

Neither benefit nor harm was shown when using HA to maintain hemodynamic stability in the perioperative period when compared with crystalloids or any other colloidal volume substitute [4-6]. In a recent study, the effects of crystalloids and 
colloids, including HA, on pulmonary edema in hypovolemic septic and non-septic patients with, or at risk of, acute lung injury/ acute respiratory distress syndrome were assessed.68 Pulmonary edema and lung injury score were not affected by the type of fluid indicating that HA was not superior to cheaper alternatives [7]. In a cohort, multicenter, observational study of 3147 ICU patients, the use of HA in European ICUs and its relationship to outcome were assessed [8]. The indication for giving albumin was not specified (hypovolemia or hypoalbuminemia). Three hundred and fifty-four patients (11.2\%) received albumin and 2793 patients $(88.8 \%)$ did not. Albumin administration was associated with decreased survival in this population of acutely ill patients. An international prospective cohort study including 1013 ICU patients needing fluid resuscitation for shock documented that the use of hyper oncotic albumin (20\% HA) was significantly associated with occurrence of negative renal events (two-fold increase in creatinine or need for dialysis) and an increased risk of death in ICU [9].

International guidelines for the management of severe sepsis and septic shock do not specifically recommend the use of HA for volume replacement for hemodynamic stabilization in this setting [10]. Shorter hospital stays and lower costs were shown when using hyper oncotic HA for correction of hypovolemia patients with liver disease. Two studies, which were more than $15 \mathrm{yr}$ old, reported reduced disability after using hyper oncotic albumin in brain injury. This review conflicts with negative results from large studies showing increased mortality after the use of HA in brain injury patients [11] and increased incidence of renal failure in ICU patients after 20\% HA [12]. Despite these meta-analyses, it remains unclear when to use HA. An evaluation in 53 hospitals in the USA showed that based on guidelines developed by the University Health System Consortium (UHC), HA was inappropriately used for $57.8 \%$ of adult patients and $52.2 \%$ of pediatric patients $[13,14]$. It is necessary to consider topical issues related to the fundamental knowledge for the effective and adequate use of albumin drugs in clinical practice. Before examine topic of methods, indications and contraindications the use albumin solutions it is necessary determine: what type albumin we using? Is it native or commercial types? What is their difference and is this knowledge important for the medical practitioner?

\section{Native Albumin}

Albumins (lat.: Albus, White) are simple water-soluble proteins. The molecule of albumin is an ellipse of $3 \times 15 \mathrm{~nm},(3.6 \mathrm{Nm})$ that consists of a single polypeptide chain. It's a low molecular weight protein. The relative molecular weight of albumin is approximately 65000 Dt. Native albumins is synthesized in the liver at a rate of about 10-15 mg per day. The $1 \mathrm{~g}$ of native albumin carries $20 \mathrm{ml}$ of water into the vessels. The scheme of hydrophobic protein-ligand binding is shown in (Figure 1).

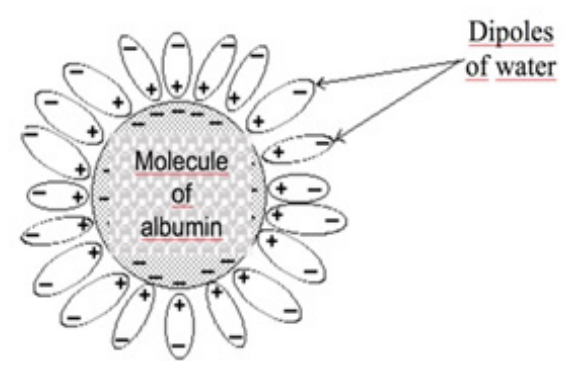

Figure 1: Protein-ligand hydrophobic binding.

\section{Commercial Albumin}

Commercial albumin is a stabilized and pasteurized native albumin. To date, there is a problem of quantitative content of stabilizers and other additional substances in the commercial preparation of albumin. The main stabilizers of albumin, their role and influence on organism were presented in Figure $2[15,16]$.

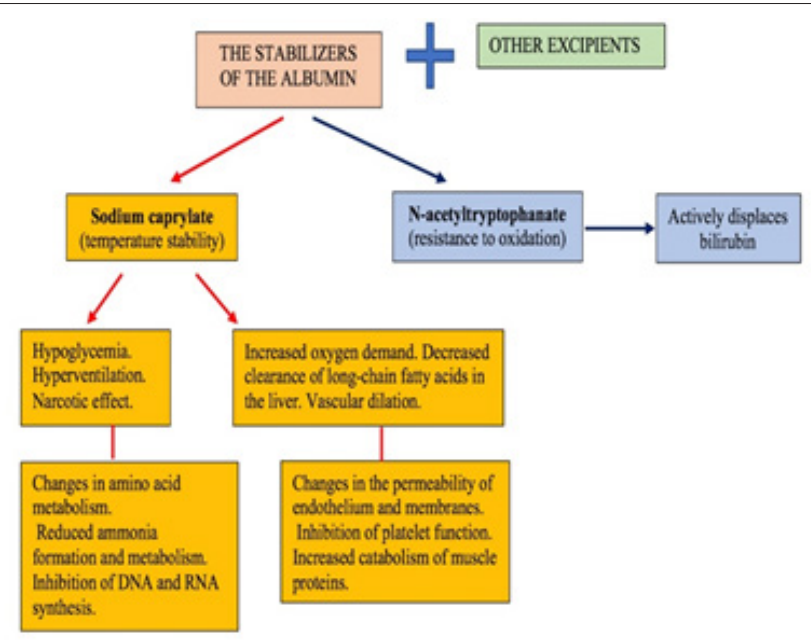

Figure 2: The main stabilizers of albumin, their role and influence. 
Figure 2 is shown that composition of the commercial solution of albumin contains the various preservatives and stabilizers. Among them, the main ones are $\mathrm{N}$-acetyltryptophanate and sodium caprylate. $\mathrm{N}$-acetyltryptophanate to protect the protein from oxidative stress and to stabilize it for heat treatment which is applied for virus inactivation. In addition, it is important to say that $\mathrm{N}$-acetyl tryptophan competes for active binding centers with bilirubin. Therefore, the amount of $\mathrm{N}$-acetyltryptophanate affects the sorption capacity of stabilized albumin in relation to bilirubin. In the end this determines the efficacy application of albumin with the aim of detoxication in hyperbilirubinemia. Sodium caprylate is the second and mandatory preservative that provides temperature stability of albumin molecules during pasteurization. It is very important to note that sodium caprylate causes a large number of serious side effects, such as: hypoglycemia, hyperventilation, increases tissue oxygen demand, prevents the metabolism of amino acids, inhibits the synthesis of DNA and RNA, violates the permeability of the endothelium and membranes, increases the catabolism of muscle proteins, inhibits platelet function, etc.

In connection with the toxicity of sodium caprylate control over the quality of the Food and Drug Administration (FDA) considers necessary to carry the index of its contents to the security settings of solutions of albumin. It is also known that the binding capacity of commercial albumin is significantly lower than that of native albumin due to the congestion of its binding centers with stabilizers and other additional substances. The lack of control over the content of lipids and fatty acids at the stages of the technological process of albumin production affects its binding capacity and transport function. Therefore, as an additional indicator of the quality of albumin drugs, clinicians in many countries propose to introduce into the regulatory documentation a quantitative assessment of functional activity - binding capacity (binding capacity/sorption capacity).

Today companies which produce commercial albumin in different countries do not have a single approach to solving this problem. It follows from this that patients receiving albumin drugs on the background of drug treatment are exposed to high concentrations of free active substance. This naturally determines the risk of exceeding pharmacological and side effects for the patient, which directly threatens his life, and the detoxification function of commercial albumin is doubtful. Also, necessary aware that some medications can compete for binding centers in albumin molecule with bilirubin and among themselves. Only these facts are enough to not only take a critical look at the results of the study of domestic and foreign authors, based on the meta-analysis of the use of commercial albumin, but also with great caution to follow their recommendations regarding the universality of its methods of application, indications and contraindications. The thoughtless and blind imposition by some domestic authors of "universal" foreign recommendations for the use of commercial albumin against the background of the lack of a single form of it is not only scientifically doubtful, but also clinically unsafe for the patient. For example, consider the action of two variants of commercial albumin (Figure 3).

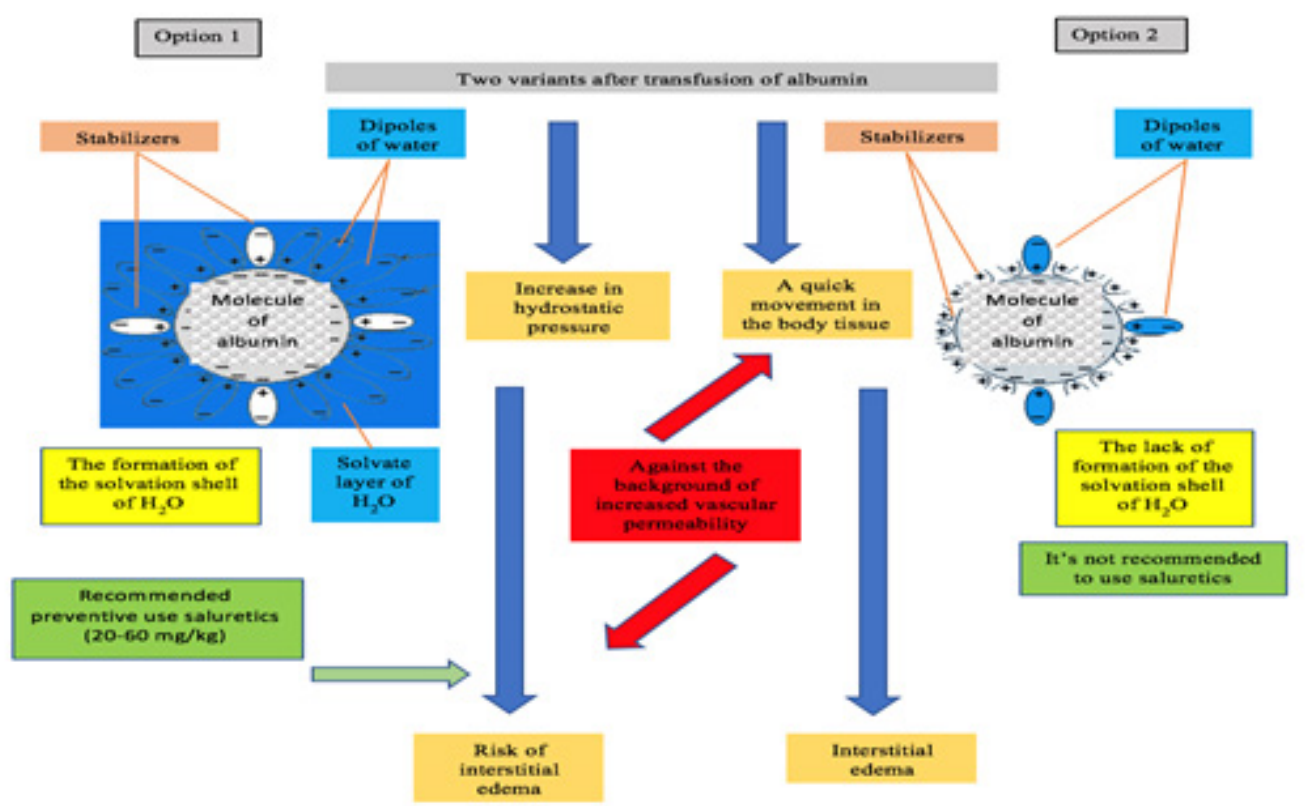

Figure 3: The scheme action of the two options of commercial albumin.

In option 1 stabilizers block a small number of binding centers. In this case the reserve binding capacity of albumin remains high enough. This variant of stable albumin absorbs a significant amount of water. As a result, the hydrostatic pressure in the vessels increases. Therefore, to prevent the risk of interstitial edema (especially against the background of increased capillary permeability), after transfusion of albumin, it is recommended to immediately administer diuretics (saluretics at a dose of 20-60 mg/ $\mathrm{kg}$ ). This achieves anti-edema and detoxification effects $[17,18]$.

On the contrary, in Option 2 stabilizers block many binding centers. Indicator the reserve binding capacity of albumin are low, 
and the sorption of water molecules is insignificant. As a result, against the background of increased capillary permeability, albumin quickly leaves the vascular bed and passes into interstitial tissues, causing or increasing edema. In this connection, the preventive use of diuretics is ineffective $[19,20]$. To date, the lack of necessary knowledge about the properties of commercial albumin, its various variants, among doctors generates numerous discussions with diametrically opposed views on the method of its application.

Therefore, for effective and adequate use of albumin clinicians need to have the following data:

1. The degree of hydrophobicity of toxemia;

2. Indicator of the reserve of albumin binding capacity;

3. Calculated index of intoxication.

Only based on the above indicators can be estimated:

1. Transport function of albumin;

2. Detoxification function of the liver;

3. Degree of blocking of albumin binding centers;

4. In combination with hydrophilic indicators of endotoxemia in dynamics, to estimate the degree of Endotoxicities, the effectiveness of hem correction and detoxification methods.

For effective use of albumin as an endogenous source of amino acids, the following conditions are necessary:

1. No circulating blood volume (CBV) deficit

2. The absence of diseases that disorder the process of absorption and enzymatic activity of the stomach.

3. Preservation of function protein synthesis in the liver.

When albumin is not used, or its use is not justified:

a. In conditions of increased capillary permeability albumin very quickly leaves the vascular bed and captures water, causing interstitial edema into the different tissues.

b. It is not recommended to use solutions of albumin in chronic nephrosis, because albumin is quickly excreted by the kidneys.

c. The use transfusion of album as a source of protein in patients suffering from intestinal malabsorption, chronic pancreatitis, chronic liver cirrhosis, body weight deficit after fasting, serious CBV deficiency is not justified.

d. It should also be known that the banal transfusion of protein preparations in the multiple organ dysfunction syndrome does not correct hypoproteinemia due to violations in the physiological chain of protein synthesis. Therefore, the doctor's argument: "for the correction of hypoproteinemia recommended transfusion of albumin" sounds at least incorrect!

In what cases transfusion of albumin is adequate and safe: Albumin should be used mainly in chronic hepatitis that accompanied by hypoalbuminemia; edematous syndrome caused by hypoalbuminemia in the absence of severe intoxication.

\section{Conclusion}

To date, there is no standardized and unified technology to produce commercial albumin. Produced by various pharmaceutical company's albumin has different physical and chemical properties. A study of application of commercial albumin should be conducted either within the same manufacturer or by comparing the specific clinical effect of albumin which was produced by different manufacturers. Unfortunately, this approach of analysis is completely absent in the medical literature. Therefore, the experience of using albumin by some clinicians a priori is not a guide for others, and the discussions held on the pages of medical journals, debates at conferences, thoughtless copying of clinical of protocols without proper fundamental knowledge, there is scientific ignorance and clinical illiteracy.

\section{References}

1. F Bunn, C Lefebvre, A Li Wan Po, L Li, I Roberts, et al. (2000) The Albumin Reviewers. Human albumin solution for resuscitation and volume expansion in critically ill patients. Cochrane Database Syst Rev 9(11): CD001208.

2. S Finfer, R Bellomo, N Boyce, J French, J Myburgh, et al. (2004) A comparison of albumin and saline for fluid resuscitation in the intensive care unit. N Engl J Med 350(22): 2247-2256.

3. Haynes G, Navickis R, Wilkes M (2003) Albumin administration: what is the evidence of clinical benefit? A systematic review of randomized controlled trials. European Journal of Anesthesiology 20(10): 771-793.

4. Boldt J, Schöllhorn T, Mayer J, Piper S, Suttner S (2006) The value of an albumin-based intravascular volume replacement strategy in elderly patients undergoing major abdominal surgery. Anesth Analg 103(1): 191-199.

5. Nicholson JP, Wolmarans MR, Park GR (2000) The role of albumin in critical illness, Br J Anaesth 85(4): 599-610.

6. Wilkes MM, Navickis RJ (2001) Patient survival after human albumin administration-a meta-analysis of randomized controlled trials. Ann Intern Med 135(3): 149-164.

7. Van der Heijden M, Verheij J, Van Nieuw Amerongen GP, Groeneveld AB (2009) Crystalloid or colloid fluid loading and pulmonary permeability, edema, and injury in septic and nonpeptic critically ill patients with hypovolemia. Crit Care Med 37(4): 1275-1281.

8. Vincent JL, Sakr Y, Reinhart K (2005) 'Sepsis Occurrence in Acutely Ill Patients' Investigators is albumin administration in the acutely ill associated with increased mortality? Results of the SOAP study. Crit Care 9(6): R745-R754.

9. Schortgen F, Girou E, Daye N, Brochard L, For the CRYCO Study Group (2008) The risk associated with hyper oncotic colloids in patients with shock. Intensive Care Med 34(12): 2157-2168.

10. Dellinger RP, Levy MM, Carlet JM, Parker MM, Jaeschke R, et al. (2008) Surviving Sepsis Campaign International guidelines for management of severe sepsis and septic shock: 2008. Crit Care Med 36(1): 296-327.

11. Myburgh J, Cooper J, Finfer S, SAFE Study Investigators; George Institute for International Health, et al. (2007) Saline or albumin for fluid resuscitation in patients with traumatic brain injury. N Engl J Med 357(9): 874-884

12.(2000) Technology Assessment: Albumin, Non-protein Colloid, and Crystalloid Solutions, Oak Book, IL, University Health System Consortium, USA. 
13. Tanzi M, Gardner M, Megellas M, Lucio S, Restino M (2003) Evaluation of the appropriate use of albumin in adult and pediatric patients. Am J Health Syst Pharm 60(13): 1330-1335.

14. Dongping Zhong, Abderrazzak Douhal, Ahmed H Zewail (2000) Femtosecond studies of protein-ligand hydrophobic binding and dynamics: Human serum albumin. Proc Natl Acad Sci USA 97(26): 14056-14061.

15. Rosenoer V M, Oratz M, Rothschild M (1977) Albumin Structure, Function, and Uses. Pergamon, Oxford.

16. Yamasaki K, Miyoshi T, Maruyama T, Takadate A, Otagiri M (1994) Biol Pharm Bull 17: 1656-1662.

17. Margaret Duffy, Shashank Jain, Nicholas Harrell, Neil Kothari, Alluru S Reddi (2015) Albumin and Furosemide Combination for Management of
Edema in Nephrotic Syndrome: A Review of Clinical Studies. Cells 4(4): 622-630.

18. Davison AM, Lambie AT, Verth AH, Cash JD (1974) Salt-poor human albumin in management of nephrotic syndrome. Br Med J 1(5906): 481484.

19. Dorhout EJ, Roos JC, Boer P, Yoe OH, Simatupang TA (1979) Observations on edema formation in the nephrotic syndrome in adults with minimal lesions. Am J Med 67(3): 378-384.

20. Geers AB, Koomans HA, Roos JC, Boer P, Dorhout Mees EJ (1984) Functional relationships in the nephrotic syndrome. Kidney Int 26(3): 324-330. 